ISAHP 2003, Bali, Indonesia, August 7-9, 2003

\title{
PRODUCT CONCEPT SELECTION USING A FUZZY ANALYTIC HIERARCHY PROCESS
}

\author{
Ade Febransyah ${ }^{1}$ and J. Bely Utarja \\ Workgroup for Innovation in Decision Making (WIDE) \\ Prasetiya Mulya Graduate School of Management, Jakarta, Indonesia
}

\begin{abstract}
Keywords: Multiple criteria decision making (MCDM), analytic hierarchy process, fuzzy set theory.
Summary: Product concept selection at the preliminary design stage is a multi criteria decision making $(M C D M)$ problem. Decisions made during this stage are characterized by imprecise and uncertain requirements. Selecting the right product concept is a critical task since it determines whether or not the product is worth developing. This paper presents the framework of product concept selection that integrates the fuzzy set theory and the analytic hierarchy process (AHP). In the proposed approach, the fuzzy set theory is employed in performing "pairwise comparison" between competing alternatives and a "reference" on each of the criteria. The comparisons are also used to obtain the relative importance of criteria with respect to the overall objective. The use of a reference is due to the difficulty in consistently comparing concepts to one another. Once pairwise comparisons are completed, vector aggregates are computed through use of a original AHP method and fuzzy arithmetic operations. A numerical example is presented to illustrate the approach.
\end{abstract}

\section{Introduction}

In today's fast-paced competitive market, each manufacturing company strives to launch a new product better and quicker. Launching a new product that will be successful in the market requires a series of right decisions early at the design stage. One of decisions that need to be correctly made during the design stage is selecting the best product concept that is worth developing. Product concept selection belongs to multi criteria decision-making (MCDM) problems. In MCDM problems, a decision maker has to pick the best concept among a set of alternatives or product concepts based on a set of criteria or attributes. Comparing alternatives or product concepts to one another and ranking them are the pivotal roles in making the decision in such cases.

Product concept selection during product development process is an iterative process that narrows the number of concepts quickly and selects the best concept. Several concept selection methods have been proposed (Pahl, 1996; Pugh, 1990). In ranking the product concepts, it is commonly assumed that decision makers can assign the relative weight of decision criteria and evaluate each alternative with respect to each selection criterion. However, in case of conflicting alternatives, the task of picking the best concept becomes extremely difficult due to the imprecise or ambiguous data, which is norm in this type of decision problems (Aouam, 2003). Therefore, a new approach is required to perform product concept selection in product development process. The new approach should be robust enough for handling impreciseness of the product concept at the preliminary design stage.

During product development process, decision makers often deal with objects that are difficult to describe. In the absence of complete and precise information, the fuzzy set theory becomes an effective tool for modeling complex systems. On the other hand, the analytic hierarchy process (AHP) becomes extensively used in dealing with MCDM problems. An important advantage of using AHP is its ability to help decision

${ }^{1}$ Corresponding author.

E-mail address: afebran@pmulya.ac.id 
makers detect inadvertent misjudgments in pairwise comparisons. The objective of this paper is to present a Fuzzy Analytic Hierarchy Process with a Reference (FUZAR), a new approach that integrates the fuzzy set theory and the analytic hierarchy process using a reference in selecting the best product concept.

\section{An Overview of Concept Selection in Product Development}

After identifying a set of customer needs and target specifications, a product development team will generate a number of product concepts from which the team will select the best one. As previously mentioned, product concept selection is an iterative process that includes concept screening and concept scoring. Figure 1 shows the successive and narrowing and temporary widening of a set of concept during concept development phase (Ulrich and Eppinger, 2000).

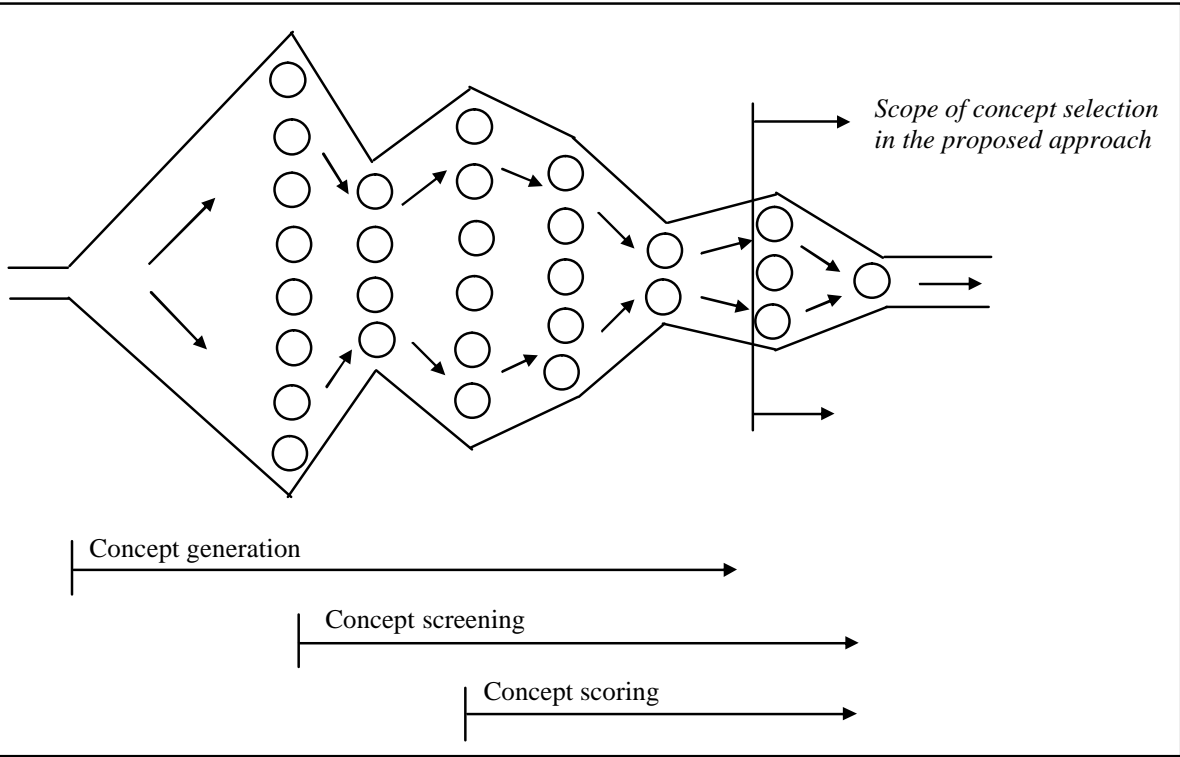

Figure 1. Concept development phase

The purpose of concept screening is to narrow the number of product concept quickly and to improve the concept (Pugh, 1990). There are three possible outcomes resulted from the concept screening: (1) superior concept (2) inferior concept and (3) revised and/or new concept. A superior concept is a concept that is worth considering to be further assessed, while an inferior concept needs to be thrown out since it is not worth considering. In some cases, one concept is actually worth considering with a minor revision or there can be certain concepts that can be combined into a new concept. The new concept here incorporates all good qualities coming from each concept. After having a set of concept candidates consisting of superior concepts and revised or new concepts, the concept scoring then takes place. At this stage, the product development team weighs the relative weight of the selection criteria and evaluates each product concept with respect to each selection criterion. The concept scores are determined by the weighted sum of the rating. The concept with the highest score is then selected. As seen in Figure 1, the scope of concept selection in this research only covers the last stage of concept scoring.

Given the imprecision of the concept description at the preliminary design stage, it is very difficult to consistently compare concept to one another. In the proposed approach, it is of interest to use a reference concept against which all other concepts are compared. The reference can be an industry standard or a commercially available product, a best-in-class benchmark product, an earlier generation of the product, any one of the concepts under consideration, or a combination of subsystem assembled to represent the best features of different products (Ullrich and Eppinger, 2000). 
When available, it is always recommended to use objective metrics as the basis for evaluating a product concept with respect to a criterion. For example, a good approximation of product cost is the number of parts in a design. Similarly, a good approximation of manufacturing leadtime is the number of operations or processes required to produce a product. The use of the objective metrics will help us minimize the judgmental nature of the evaluating process.

\section{The Framework of Fuzzy AHP with a Reference (FUZAR)}

In general, AHP consists of five steps: (1) breaking down the decision into a hierarchy of decision elements, (2) performing pairwise comparison of decision elements, (3) checking the consistency of the input data, (4) computing the relative weights of the decision elements, (5) aggregating the relative weights of the decision elements in order to obtain a numerical outcome. We assume the reader is familiar with the details of AHP; otherwise the reader is referred to the comprehensive text by (Saaty, 1980).

Figure 2 is a three level hierarchy that will be used for illustrative purposes in this paper.

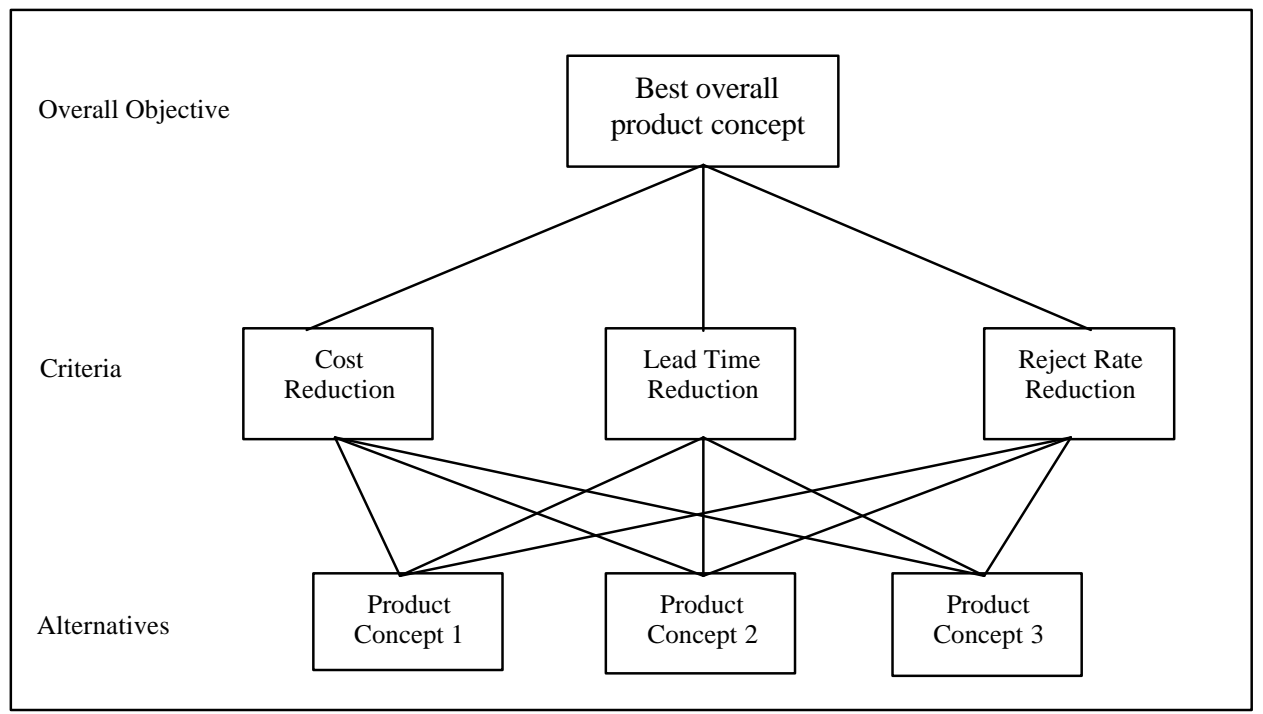

Figure 2. The structure of AHP

The first level is the overall objective of the decision problem. The second level is a list of criteria to be considered in achieving the overall objective. The third level is the set of alternatives to be evaluated using the AHP methodology. For simplicity, there are only three product concepts, $A_{1}, A_{2}, A_{3}$ and three criteria, Cost Reduction, Lead Time Reduction, Reject Rate Reduction to be considered.

\section{The Mechanic of AHP with a Reference}

In FUZAR, a reference is used in performing pairwise comparison in an effort to achieve consistency. The pairwise comparison matrix between a product concept and a reference with respect to criteria $(C R=$ Cost Reduction, $L T R=$ Lead Time Reduction, and $R R R=$ Reject Rate Reduction) is shown in the following table:

\begin{tabular}{|l|c|c|c|}
\hline & Concept 1 & Concept 2 & Concept 3 \\
\hline CR & $\mathrm{a}_{1, \mathrm{C}}$ & $\mathrm{a}_{2, \mathrm{C}}$ & $\mathrm{a}_{3, \mathrm{C}}$ \\
\hline LTR & $\mathrm{a}_{1, \mathrm{~L}}$ & $\mathrm{a}_{2, \mathrm{~L}}$ & $\mathrm{a}_{3, \mathrm{~L}}$ \\
\hline RRD & $\mathrm{a}_{1, \mathrm{R}}$ & $\mathrm{a}_{2, \mathrm{R}}$ & $\mathrm{a}_{3, \mathrm{R}}$ \\
\hline
\end{tabular}


The corresponding original AHP's pairwise comparison matrices are:

\begin{tabular}{|l|c|c|c|}
\hline & Concept 1 & Concept 2 & Concept 3 \\
\hline Concept 1 & $\mathrm{a}_{1, \mathrm{C}} / \mathrm{a}_{1, \mathrm{C}}$ & $\mathrm{a}_{1, \mathrm{C}} / \mathrm{a}_{2, \mathrm{C}}$ & $\mathrm{a}_{1, \mathrm{C}} / \mathrm{a}_{3, \mathrm{C}}$ \\
\hline Concept 2 & $\mathrm{a}_{2, \mathrm{C}} / \mathrm{a}_{1, \mathrm{C}}$ & $\mathrm{a}_{2, \mathrm{C}} / \mathrm{a}_{2, \mathrm{C}}$ & $\mathrm{a}_{2, \mathrm{C}} / \mathrm{a}_{3, \mathrm{C}}$ \\
\hline Concept 3 & $\mathrm{a}_{3, \mathrm{C}} / \mathrm{a}_{1, \mathrm{C}}$ & $\mathrm{a}_{3, \mathrm{C}} / \mathrm{a}_{2, \mathrm{C}}$ & $\mathrm{a}_{3, \mathrm{C}} / \mathrm{a}_{3, \mathrm{C}}$ \\
\hline
\end{tabular}

Matrix 1a

\begin{tabular}{|l|c|c|c|}
\hline & Concept 1 & Concept 2 & Concept 3 \\
\hline Concept 1 & $\mathrm{a}_{1, \mathrm{~L}} / \mathrm{a}_{1, \mathrm{~L}}$ & $\mathrm{a}_{1, \mathrm{~L}} / \mathrm{a}_{2, \mathrm{~L}}$ & $\mathrm{a}_{1, \mathrm{~L}} / \mathrm{a}_{3, \mathrm{~L}}$ \\
\hline Concept 2 & $\mathrm{a}_{2, \mathrm{~L}} / \mathrm{a}_{1, \mathrm{~L}}$ & $\mathrm{a}_{2, \mathrm{~L}} / \mathrm{a}_{2, \mathrm{~L}}$ & $\mathrm{a}_{2, \mathrm{~L}} / \mathrm{a}_{3, \mathrm{~L}}$ \\
\hline Concept 3 & $\mathrm{a}_{3, \mathrm{~L}} / \mathrm{a}_{1, \mathrm{~L}}$ & $\mathrm{a}_{3, \mathrm{~L}} / \mathrm{a}_{2, \mathrm{~L}}$ & $\mathrm{a}_{3, \mathrm{~L}} / \mathrm{a}_{3, \mathrm{~L}}$ \\
\hline
\end{tabular}

Matrix $1 b$

\begin{tabular}{|l|c|c|c|}
\hline & Concept 1 & Concept 2 & Concept 3 \\
\hline Concept 1 & $\mathrm{a}_{1, \mathrm{R}} / \mathrm{a}_{1, \mathrm{R}}$ & $\mathrm{a}_{1, \mathrm{R}} / \mathrm{a}_{2, \mathrm{R}}$ & $\mathrm{a}_{1, \mathrm{R}} / \mathrm{a}_{3, \mathrm{R}}$ \\
\hline Concept 2 & $\mathrm{a}_{2, \mathrm{R}} / \mathrm{a}_{1, \mathrm{R}}$ & $\mathrm{a}_{2, \mathrm{R}} / \mathrm{a}_{2, \mathrm{R}}$ & $\mathrm{a}_{2, \mathrm{R}} / \mathrm{a}_{3, \mathrm{R}}$ \\
\hline Concept 3 & $\mathrm{a}_{3, \mathrm{R}} / \mathrm{a}_{1, \mathrm{R}}$ & $\mathrm{a}_{3, \mathrm{R}} / \mathrm{a}_{2, \mathrm{R}}$ & $\mathrm{a}_{3, \mathrm{R}} / \mathrm{a}_{3, \mathrm{R}}$ \\
\hline
\end{tabular}

Matrix 1c

The relative weight of criteria with respect to the overall objective is $C R: L T R: R R R=w 1: w 2: w 3$. The corresponding original AHP's pairwise comparison matrix is:

\begin{tabular}{|l|c|c|c|}
\hline & CR & LTR & RRR \\
\hline CR & $w_{1} / w_{1}$ & $w_{1} / w_{2}$ & $w_{1} / w_{3}$ \\
\hline LTR & $w_{2} / w_{1}$ & $w_{2} / w_{2}$ & $w_{2} / w_{3}$ \\
\hline RRR & $w_{3} / w_{1}$ & $w_{3} / w_{2}$ & $w_{3} / w_{3}$ \\
\hline
\end{tabular}

Matrix 2

Once the pairwise comparison matrices such as Matrix 1 and Matrix 2 are built, the relative weight of each alternative with respect to criteria and the relative weight of each criterion on the overall objective can be calculated through use of a technique suggested by (Saaty, 1977, 1980, 1982). A method of computing vectors of relative weight is in Appendix A. The aggregation process for obtaining the concept priority can be done through use of the following matrix operation:

\begin{tabular}{|c|c|c|c|c|c|c|c|}
\hline & $\begin{array}{l}\text { Normalized Cost } \\
\text { Reduction Relative } \\
\text { to Reference's }\end{array}$ & $\begin{array}{l}\text { Normalized Lead } \\
\text { Time Reduction } \\
\text { Relative to } \\
\text { Reference's } \\
\end{array}$ & $\begin{array}{c}\text { Normalized Reject } \\
\text { Rate Reduction } \\
\text { Relative to } \\
\text { Reference's } \\
\end{array}$ & \multirow{4}{*}{$X$} & $\begin{array}{c}\text { Vector relative } \\
\text { weight of criteria }\end{array}$ & \multirow{4}{*}{$=$} & $\begin{array}{l}\text { Normalized } \\
\text { Priorities }\end{array}$ \\
\hline Concept 1 & $a_{1, c}\left(a_{1, c}+a_{2, c}+a_{3, c}\right)$ & $\overline{a_{1, L} /\left(a_{1, L}+a_{2, L}+a_{3, L}\right)}$ & $a_{1, R} /\left(a_{1, R}+a_{2, R}+a_{3, R}\right)$ & & $w_{1} /\left(w_{1}+w_{2}+w_{3}\right)$ & & $\mathrm{X}_{1}$ \\
\hline Concept 2 & $a_{2, d} d\left(a_{1, c}+a_{2, c}+a_{3, c}\right)$ & $\mathrm{a}_{2, \mathrm{~L}} /\left(\mathrm{a}_{1, \mathrm{~L}}+\mathrm{a}_{2, \mathrm{~L}}+\mathrm{a}_{3, \mathrm{~L}}\right)$ & $a_{2, \mathrm{R}} /\left(a_{1, R}+a_{2, \mathrm{R}}+a_{3, \mathrm{R}}\right)$ & & $\mathrm{w}_{2} /\left(\mathrm{w}_{1}+\mathrm{w}_{2}+\mathrm{w}_{3}\right)$ & & $\mathrm{X}_{2}$ \\
\hline Concept 3 & $a_{3, c} /\left(a_{1, c}+a_{2, c}+a_{3, c}\right)$ & $\mathrm{a}_{3, \mathrm{~L}} /\left(\mathrm{a}_{1, \mathrm{~L}}+\mathrm{a}_{2, \mathrm{~L}}+\mathrm{a}_{3, \mathrm{~L}}\right)$ & $a_{3, R} /\left(a_{1, R}+a_{2, R}+a_{3, R}\right)$ & & $\mathrm{w}_{3} /\left(\mathrm{w}_{1}+\mathrm{w}_{2}+\mathrm{w}_{3}\right)$ & & $\mathrm{X}_{3}$ \\
\hline
\end{tabular}

The Mechanic of Fuzzy AHP with a Reference

Fuzzy AHP accommodates impreciseness of the product concept at the preliminary design stage. The assigned values in previous matrix 1 and matrix 2 are represented in terms of fuzzy numbers, in this case triangular fuzzy numbers. 
For example: Concept 1's Cost Reduction relative to the Reference in matrix 1 that is $a_{1, C}$ is represented by $\mathbf{A}_{1, \mathrm{C}}$

$$
\mathbf{A}_{1, \mathrm{C}} \equiv \mu_{\mathbf{A}}(\mathrm{x})=\left\{\begin{array}{cl}
2 \frac{x-c_{1}}{c_{2}-c_{1}} & \text { for } c_{1} \leq x \leq \frac{c_{1}-c_{2}}{2} \\
2 \frac{x-c_{2}}{c_{1}-c_{2}} & \text { for } \frac{c_{1}-c_{2}}{2} \leq x \leq c_{2} \\
0 & \text { otherwise }
\end{array}\right.
$$

by substituting $c 1, c 2$ with values of 4 and 5, respectively, we will get the following fuzzy membership function :

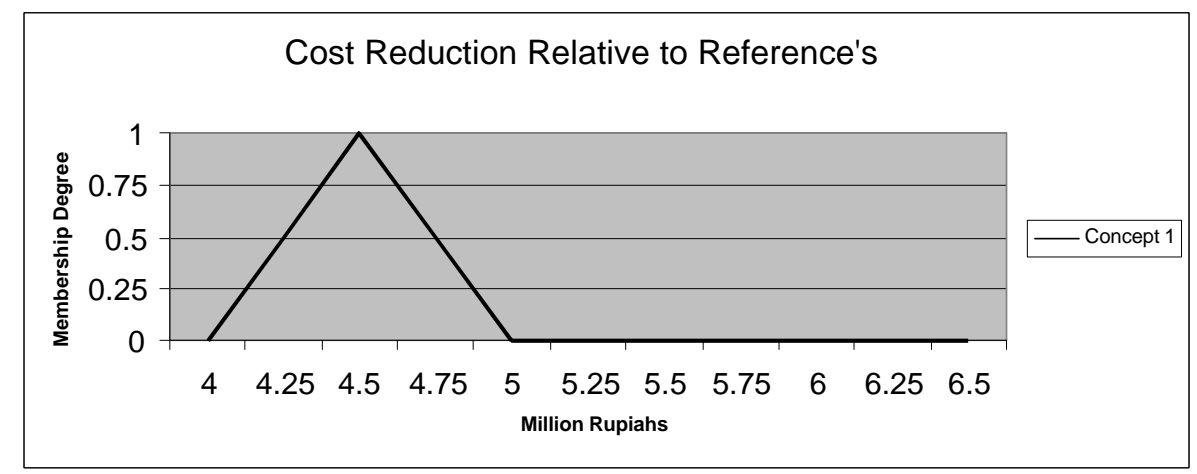

Figure 3. Fuzzy Membership Function

To calculate the concept priority through matrix operation as described in AHP with a reference, an interval arithmetic is used. A fuzzy number can be represented as a series of intervals for every $\lambda$ cut. $\lambda$ cut of a fuzzy set is defined as a crisp interval for a particular degree of membership, $\alpha$. $\alpha$ can take values between 0 and 1 .

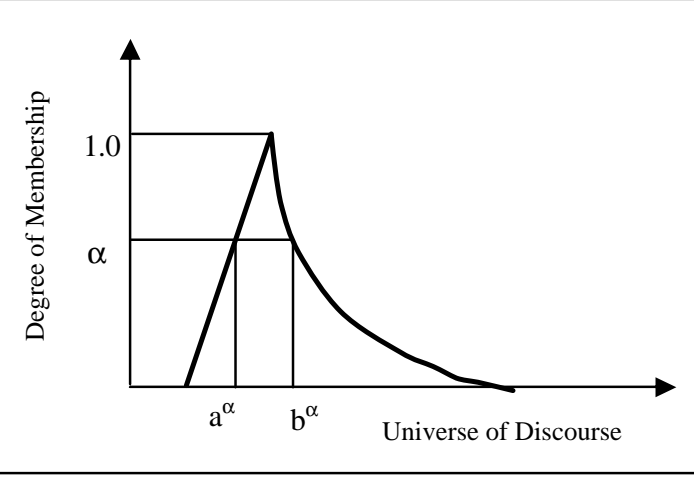

Figure 4. Interval Arithmetic for Fuzzy Operations 
For any two intervals $[a, b]$ and $[\mathrm{d}, \mathrm{e}]$, the arithmetic operations are performed in the following way:

$$
\begin{array}{lcl}
\text { Addition } & : & {[\mathrm{a}, \mathrm{b}]+[\mathrm{d}, \mathrm{e}]=[\mathrm{a}+\mathrm{d}, \mathrm{b}+\mathrm{e}]} \\
\text { Multiplication } & : & {[\mathrm{a}, \mathrm{b}] \cdot[\mathrm{d}, \mathrm{e}]=[\min (\mathrm{ad}, \mathrm{ae}, \mathrm{bd}, \mathrm{be}), \max (\mathrm{ad}, \mathrm{ae}, \mathrm{bd}, \mathrm{be})]} \\
\text { Division } & : & {[\mathrm{a}, \mathrm{b}] /[\mathrm{d}, \mathrm{e}]=[\min (\mathrm{a} / \mathrm{d}, \mathrm{a} / \mathrm{e}, \mathrm{b} / \mathrm{d}, \mathrm{b} / \mathrm{e}), \max (\mathrm{a} / \mathrm{d}, \mathrm{a} / \mathrm{e}, \mathrm{b} / \mathrm{d}, \mathrm{b} / \mathrm{e})]}
\end{array}
$$

\section{A Numerical Example}

\section{Analytic Hierarchy Process with a Reference}

To describe the procedure, we give a typical example of product development problem. Suppose we are having three product concepts. We want to come up with priorities among the concepts with respect to three factors: cost, lead time and reject rate. Those factors are compared with a reference, so we can get a relative values describing three criteria: cost reduction (relative to reference's cost), lead time reduction (relative to reference's lead time) and reject rate reduction (relative to reference's reject rate reduction). The table below shows a numerical example produced by an expert:

\begin{tabular}{|l|c|c|c|}
\hline Criteria (metric) & Concept 1 & Concept 2 & Concept 3 \\
\hline Cost Reduction (M. Rupiah) & 4.5 & 6 & 5 \\
\hline Lead Time Reduction (days) & 18 & 4 & 10 \\
\hline Reject Rate Reduction (\%) & 5 & 4 & 7 \\
\hline
\end{tabular}

If we use the original AHP, the corresponding consistent pairwise comparison matrices based on the above information are:

\begin{tabular}{|r|c|c|c|}
\hline Cost Reduction & Concept 1 & Concept 2 & Concept 3 \\
\hline Concept 1 & 1.00 & 0.75 & 0.90 \\
\hline Concept 2 & 1.33 & 1.00 & 1.20 \\
\hline Concept 3 & 1.11 & 0.83 & 1.00 \\
\hline
\end{tabular}

\begin{tabular}{|r|c|c|c|}
\hline Lead Time Reduction & Concept 1 & Concept 2 & Concept 3 \\
\hline Concept 1 & 1.00 & 4.50 & 1.80 \\
\hline Concept 2 & 0.22 & 1.00 & 0.40 \\
\hline Concept 3 & 0.56 & 2.50 & 1.00 \\
\hline
\end{tabular}

\begin{tabular}{|r|c|c|c|}
\hline Reject Rate Reduction & Concept 1 & Concept 2 & Concept 3 \\
\hline Concept 1 & 1.00 & 1.25 & 0.71 \\
\hline Concept 2 & 0.80 & 1.00 & 0.57 \\
\hline Concept 3 & 1.40 & 1.75 & 1.00 \\
\hline
\end{tabular}

Based on an expert knowledge we can describe the relative weight of criteria on the overall objective. The overall objective is maximizing shareholder's value proxied by present worth. Suppose the relative weight of Cost Reduction, Lead Time Reduction, and Reject Rate Reduction on Present Worth are 4, 2, and 1 respectively, then a $1 \%$ change in Cost Reduction results in $4 \%$ change in Present Worth, a $1 \%$ change in Lead Time Reduction will result in $2 \%$ change in Present Worth and so on.

The consistent pairwise comparison matrix is shown below.

\begin{tabular}{|r|c|c|c|}
\hline & CR & LTR & RRR \\
\hline Cost Reduction & 1 & 2 & 4 \\
\hline Lead Time Reduction & 0.5 & 1 & 2 \\
\hline Reject Rate Reduction & 0.25 & 0.5 & 1 \\
\hline
\end{tabular}




\section{Consistency Testing}

Before we go further, we need to check the consistency of pairwise comparisons using the consistency index $(C I)$ and the consistency ratio $(C R)$ as follows:

$$
C I=\frac{\left(\lambda_{\max }-n\right)}{(n-1)} \quad C I=\frac{\left(\lambda_{\max }-n\right)}{(n-1)}
$$

where $\lambda_{\max }$ is the largest eigenvalue of the pairwise comparison matrix and $n$ is the number of rows of the pairwise comparison matrix. For all pairwise comparison matrices in this numerical example, it is shown that

$$
(1-\lambda)^{3}-3(1-\lambda)+2=0 \Leftrightarrow \lambda^{2}(3-\lambda)=0 ; \lambda_{\max }=3
$$

Therefore, all pairwise comparison matrices are fully consistent.

\section{Aggregation process}

\begin{tabular}{|c|c|c|c|}
\hline & $\begin{array}{l}\text { Normalized } \\
\text { Cost } \\
\text { Reduction } \\
\text { Relative to } \\
\text { Reference's }\end{array}$ & $\begin{array}{l}\text { Normalized } \\
\text { Lead Time } \\
\text { Reduction } \\
\text { Relative to } \\
\text { Reference's }\end{array}$ & $\begin{array}{c}\text { Normalized } \\
\text { Reject Rate } \\
\text { Reduction } \\
\text { Relative to } \\
\text { Reference's }\end{array}$ \\
\hline Concept 1 & 0.290 & 0.563 & 0.313 \\
\hline Concept 2 & 0.387 & 0.125 & 0.250 \\
\hline Concept 3 & 0.323 & 0.313 & 0.438 \\
\hline
\end{tabular}

Using the above information we can calculate the priorities summarized in the table below:
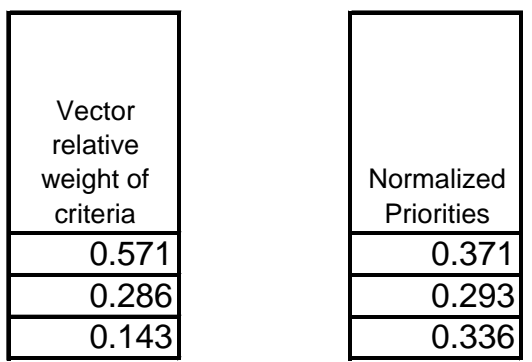

From the table above, it is obtained that Concept 1 has the highest priority followed by Concept 3 and Concept 2.

\section{Fuzzy Analytic Hierarchy Process with a Reference}

We have already discussed an expert knowledge in determining the numbers that compare alternatives and criteria. By nature, that knowledge is imprecise. So we develop a fuzzy AHP with a reference that accommodates the impreciseness. In this approach, fuzzy numbers are used to describe the assigned values instead of crisp numbers.

Suppose the fuzzy membership functions of an expert knowledge are all triangles and are shown in the following figures:

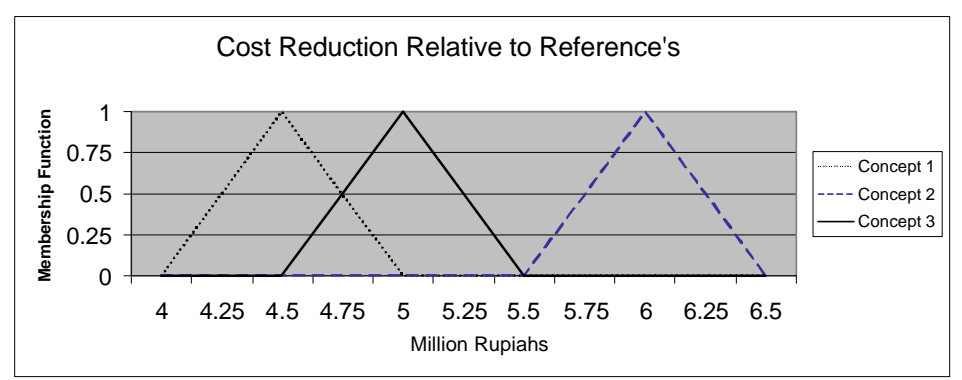



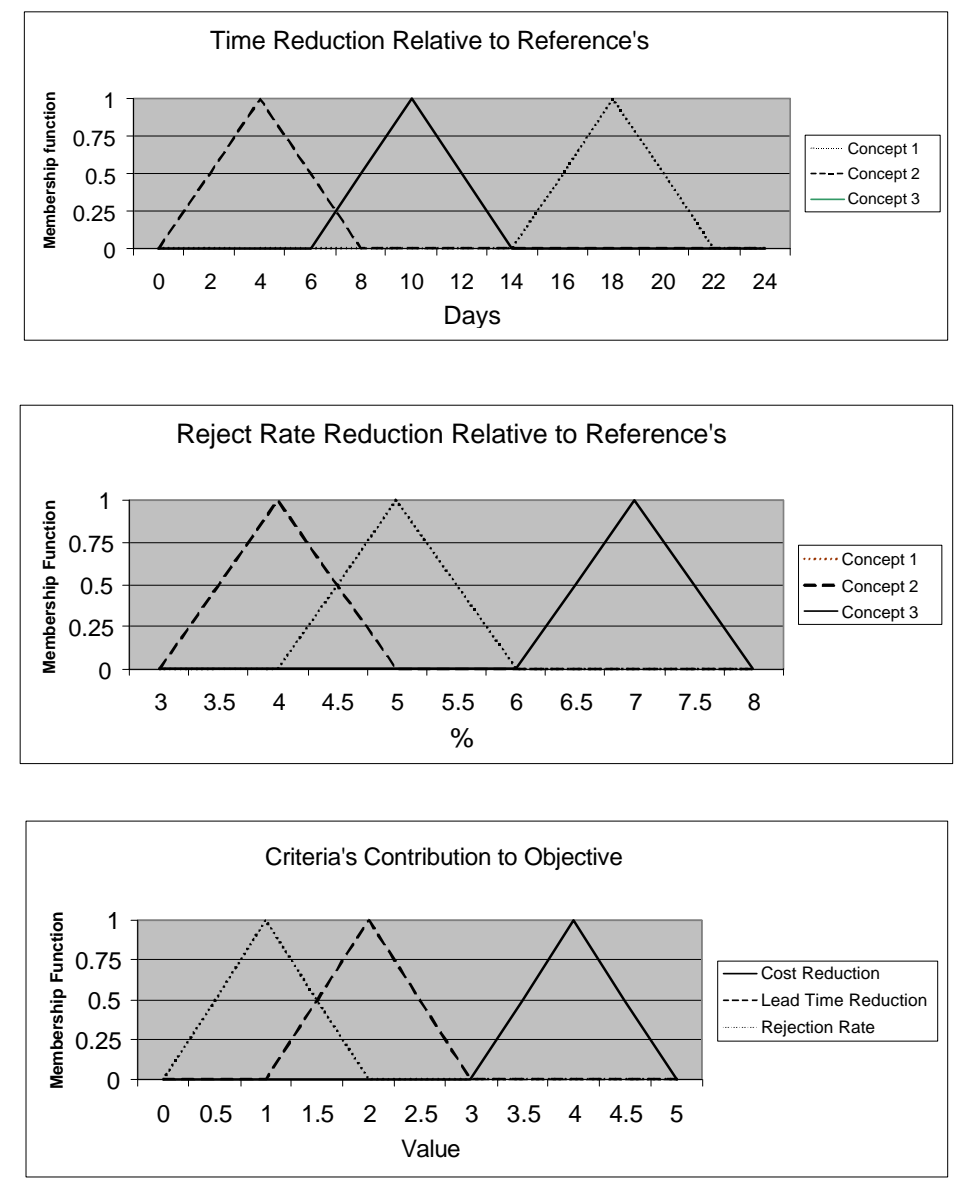

To calculate priorities between concepts, we use the fuzzy arithmetic of addition, multiplication and division. The result is consistent with Analytical Hierarchy Process with a reference that we have already discussed in the previous section. The fuzzy numbers describing the priorities are shown the following figure and table:

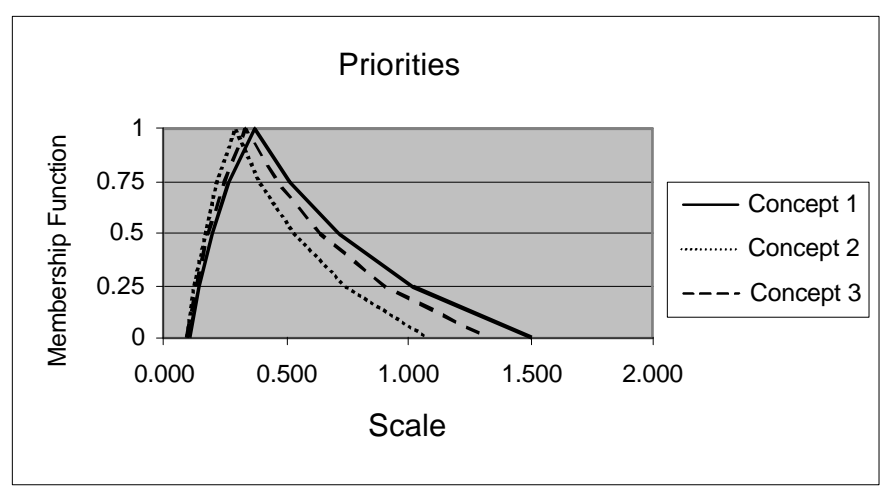

\begin{tabular}{|c|ccccccccc|}
\hline $\mathrm{a}$ & 0 & 0.25 & 0.5 & 0.75 & $\mathbf{1}$ & 0.75 & 0.5 & 0.25 & 0 \\
\hline Concept 1 & 0.102 & 0.143 & 0.197 & 0.270 & $\mathbf{0 . 3 7 1}$ & 0.513 & 0.717 & 1.022 & 1.502 \\
Concept 2 & 0.097 & 0.127 & 0.167 & 0.220 & $\mathbf{0 . 2 9 3}$ & 0.393 & 0.536 & 0.747 & 1.073 \\
Concept 3 & 0.093 & 0.130 & 0.179 & 0.246 & $\mathbf{0 . 3 3 6}$ & 0.462 & 0.642 & 0.909 & 1.324 \\
\hline
\end{tabular}


Again, the table above assigns Concept 1 the highest priority, followed by Concept 3 and Concept 2 . These results are consistent with those obtained from the original AHP. Interestingly, the values of priorities for each concept obtained from the original AHP are the same with those obtained from fuzzy AHP with $\alpha=1$.

\section{Conclusion}

A fuzzy AHP with a reference for product concept selection has been proposed and discussed. A numerical example is also presented and the results show that the fuzzy AHP gives the same ranking order as the original AHP does. Advantages of using this fuzzy AHP with a reference are the following: (1) it can accommodate the impreciseness of product concept at the preliminary design stage, (2) it can maintain consistency in pairwise comparison, (3) the result is also a fuzzy number which resembles natural human thinking when comparing alternatives. Despite those advantages, some difficulties might be encountered and need to be further investigated. One of difficulties is perhaps in absorbing an expert knowledge and represents it in terms of fuzzy numbers. Also, a further investigation needs to be done to see whether or not using different fuzzy numbers will give the same result as the original AHP does.

\section{References}

Aouam, T., Chang, S.I., and Lee,E.S. (2003), "Fuzzy MADM: An Outranking Method”, European Journal of Operational Research, Vol. 145, 317-328.

Bellman, R. and Zadeh, L.A. (1970), "Decision Making in a Fuzzy Environment”, Management Science, Vol. 17B(4), 141-164.

Bojadziev, G. and Bojadziev, M. (1997), "Fuzzy Logic for Business, Finance, and Management”, Advances in Fuzzy Systems, Applications and Theory, Vol. 6, World Scientific.

Boucher, T.O. and MacStravic, E.L. (1991), "Multiattribute Evaluation within a Present Value Framework and its Relation to the Analytic Hierarchy Process", The Engineering Economist, Vol. 37, No.1, 1-32.

Law, W.S. and Antonsson, E.K.(1994), "Implementing the Method of Imprecision: An Engineering Design Example", IEEE, Vol 10, 358-363.

Ulrich, K.T. and Eppinger, S.D. (2000), Product Design and Development, McGraw-Hill, New York.

Pahl, G. and Beitz, W. (1996), Engineering Design: A Systematic Approach, Springer-Verlag $2^{\text {nd }}$ edition, London.

Pugh, S. (1990), Total Design, Addison-Wesley, Reading, MA.

Saaty, T.L. (1977), “A Scaling Method for Priorities in Hierarchical Structures”, Journal of Mathematical Psychology, Vol. 15, No. 3, 234-281.

(1980), The Analytic Hierarchy Process, McGraw-Hill, New York.

(1982), Decision Making for Leaders: The Analytic Hierarchy Process for Decisions in a Complex World, Atlanta, GA: Lifetime Learning Publications.

Zadeh, L.A. (1965), Fuzzy sets, Information and Control, 8, 338-353. 


\section{Appendix A. Methods of Computing Vectors of Relative Weights}

\section{Method of Computing Vector of Relative Weights}

One of methods described by [Saaty 1980] is now illustrated. Consider the following matrix of pairwise comparison in ratio form:

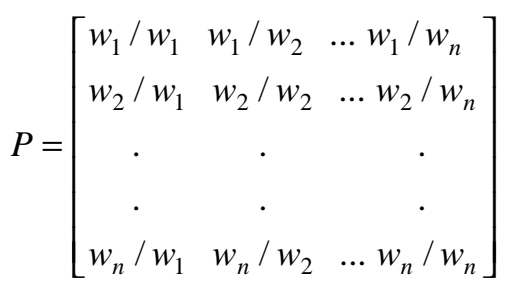

Step 1: Sum the columns of the P matrix

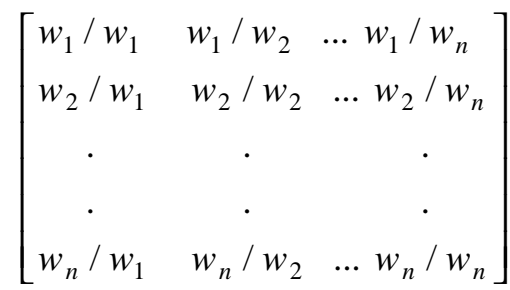

$\operatorname{Sum} \sum_{i} w_{i} / w_{1} \quad \sum_{i} w_{i} / w_{2} \quad \sum_{i} w_{i} / w_{n}$

Step 2: Divide each element in the P matrix by the column sum

$$
\left[\begin{array}{cccc}
w_{1} / \sum_{i} w_{i} & w_{1} / \sum_{i} w_{i} & \ldots & w_{1} / \sum_{i} w_{i} \\
w_{2} / \sum_{i} w_{i} & w_{2} / \sum_{i} w_{i} & \ldots & w_{2} / \sum_{i} w_{i} \\
\cdot & \cdot & & \cdot \\
\cdot & \cdot & & \cdot \\
w_{n} / \sum_{i} w_{i} & w_{n} / \sum_{i} w_{i} & \ldots & w_{n} / \sum_{i} w_{i}
\end{array}\right]
$$

Step 3: Obtain the vector of relative weights by summing the rows and dividing by the number of elements in the row

\begin{tabular}{|c|c|}
\hline Row Sums & Vector of Relative Weights \\
\hline$n w_{1} / \sum_{i} w_{i}$ & $w_{1} / \sum_{i} w_{i}$ \\
\hline$n w_{2} / \sum_{i} w_{i}$ & $w_{2} / \sum_{i} w_{i}$ \\
\hline$\cdot$ & $\cdot$ \\
$\cdot$ & $w_{n} / \sum_{i} w_{i}$ \\
\hline$n w_{3} / \sum_{i} w_{i}$ & \\
\hline
\end{tabular}

